\title{
Lack of Relationship Between Chronic Upper Abdominal Symptoms and Gastric Function in Functional Dyspepsia
}

\author{
Niels van Lelyveld · Maria Schipper • \\ Melvin Samsom
}

Received: 8 April 2007/Accepted: 3 September 2007/Published online: 12 October 2007

(C) Springer Science+Business Media, LLC 2007

\begin{abstract}
To determine the relationship between gastric function and upper abdominal sensations we studied sixty FD patients (43 female). All patients underwent three gastric function tests: ${ }^{13} \mathrm{C}$ octanoic gastric emptying test, three-dimensional ultrasonography (proximal and distal gastric volume), and the nutrient drink test. Upper abdominal sensations experienced in daily life were scored using questionnaires. Impaired proximal gastric relaxation $(23 \%)$ and a delayed gastric emptying (33\%) are highly prevalent in FD patients; however, only a small overlap exists between the two pathophysiologic disorders (5\%). No relationship was found between chronic upper abdominal symptoms and gastric function (proximal gastric relaxation, gastric emptying rate, or drinking capacity) (all $P>0.01$ ). Proximal gastric relaxation or gastric emptying rate had no effect on maximum drinking capacity $(P>0.01)$. The lack of relationship between chronic upper abdominal sensations and gastric function questions the role of these pathophysiologic mechanisms in the generation of symptoms.
\end{abstract}

Keywords Functional dyspepsia - Stomach .

Gastric emptying · 3D-ultrasonography ·

Nutrient drink test · Upper abdominal symptoms

N. van Lelyveld $(\bowtie) \cdot$ M. Samsom

Department of Gastroenterology, Gastrointestinal Research Unit, University Medical Centre Utrecht, PO Box 85500, 3508 GA,

Utrecht, The Netherlands

e-mail: n.van.lelyveld@meandermc.nl

M. Schipper

Centre of Biostatistics, University of Utrecht, Utrecht,

The Netherlands

\begin{abstract}
Abbreviations
FD Functional dyspepsia

VAS Visual analogue scale

3D-US Three-dimensional ultrasound
\end{abstract}

\section{Introduction}

Functional dyspepsia (FD) is a common disorder seen in daily clinical practice, characterized by the presence of pain or discomfort in the upper abdomen in the absence of organic, systemic, or metabolic disease [1]. Functional dyspeptic patients complain about a variety of symptoms, which are frequently intermittent, and mostly related to food intake [2]. For that reason, a subdivision of patients has been proposed, in order to clarify the heterogeneity of this disorder and to direct treatment options [3]. Attempts have been made to subdivide patients according to their symptoms; however, a large overlap of symptoms exists and many patients do not fit into one of the subgroups [1].

Currently, many efforts are being made to subdivide patients according to gastric (dys)function, and to find new ways of treating these proposed pathophysiologic disorders [4]. Three pathophysiologic mechanisms have been described as possible etiologic factors: (1) a delayed gastric emptying, (2) impaired proximal gastric accommodation, and (3) visceral hypersensitivity. Delayed gastric emptying is present in approximately $30 \%$ of FD patients, and may be one of the underlying mechanisms for symptoms (vomiting and postprandial fullness) [5]. Impaired proximal gastric relaxation may be an important etiologic factor in the pathophysiology of functional dyspepsia, considering the high prevalence of approximately $40 \%$ in FD patients, and a possible association with early satiety, weight loss, and fullness [6, 7]. Finally, an increased 
visceral sensitivity is highly frequent in FD patients, and even though difficult to measure, an important etiologic factor in the pathophysiology of FD [8]. However, when targeting specific pathophysiologic mechanisms by the use of pharmacologic agents, the effect on symptoms is questionable $[6,9,10]$. In other words, the relationship between specific upper abdominal sensations and the above-mentioned mechanisms remains to be matter of debate.

We conducted a study to assess the relationship between gastric function and upper abdominal sensations. Gastric emptying rate, proximal gastric relaxation, and maximum drinking capacity were assessed in FD patients. The symptoms experienced in daily life (chronic upper abdominal symptoms) were assessed and related to the primary outcome parameters of the gastric function tests. We hypothesised that chronic upper abdominal symptoms and specific pathophysiologic mechanisms have no correlation in functional dyspepsia.

\section{Materials and methods}

\section{Patients}

All patients visiting the outpatient clinics at our hospital, fulfilling the Rome II criteria for functional dyspepsia [1], were subjected to three non-invasive functional tests of the stomach. A total of 60 functional dyspeptic patients were prospectively evaluated; 43 female (median age 40 years; range 18-65) and 17 male (median age 37 years; range 21-64).

The inclusion criteria were (a) the presence of dyspeptic symptoms, assessed using the questionnaire described below; (b) no evidence of macroscopic inflammation of the esophageal mucosa or focal lesions of the esophagogastroduodenal mucosa at upper gastrointestinal endoscopy (performed within 1-year prior to inclusion); (c) no abnormalities seen during upper abdominal ultrasonography (performed within 1 year prior to inclusion); (d) absence of serious concomitant illness; and (e) the absence of major gastrointestinal surgery (excluding appendectomy).

The protocol was approved by the ethics committee of the University Medical Center Utrecht. All patients gave written informed consent for inclusion in the trial.

\section{Chronic dyspeptic symptoms questionnaire}

Each patient completed a reproducible dyspepsia questionnaire $[5,6,11]$. Patients were asked to score six different symptoms (pain or discomfort centered in the upper abdomen, early satiety, bloating in the upper abdomen, fullness, nausea, and vomiting) from 0 to 5 ( 0 = none, 1 = very mild; awareness of symptoms but easily tolerated, 2 = mild; tolerated without interference with usual activity, 3 = moderate; enough to cause some interference with usual activity, $4=$ severe; enough to cause significant interference with usual activity, $5=$ very severe; incapacitating with inability to work or do usual activity). For inclusion, two of these symptoms had to be scored as moderate, severe or very severe and these symptoms needed to be present for at least 12 weeks, not necessary consecutive, in the preceding 12 months.

\section{Study protocol}

All patients underwent three functional tests of the stomach on three separate days; the ${ }^{13} \mathrm{C}$-octanoic breath test, threedimensional ultrasonography of the stomach, and a nutrient drink test. The order of the three study days was arbitrary. Each of the study days started at 08:00 h after an overnight fast of at least $10 \mathrm{~h}$. The time interval between the tests was three days to 2 weeks. Patients were asked to discontinue any medication known to influence gastrointestinal motility or sensitivity for at least 7 days prior to the study, including PPI therapy. The use of narcotics, anticholinergic medication, serotonergic medication (including selective serotonin reuptake inhibitors), and antidepressants was considered an exclusion criterion. None of the patients were on NSAID therapy.

\section{${ }^{13} \mathrm{C}$-octanoic breath test}

The rate of gastric emptying was assessed using the ${ }^{13} \mathrm{C}$ octanoic breath test. The test meal consisted of two fried eggs, one slice of bread, $5 \mathrm{~g}$ margarine and $150 \mathrm{ml}$ water (total caloric value of $294 \mathrm{kcal}$ and a nutrient composition of $16 \mathrm{~g}$ protein, $16 \mathrm{~g}$ carbohydrate, $18 \mathrm{~g}$ fat) [12]. The egg yolk of one egg was labelled with $100 \mathrm{mg}{ }^{13} \mathrm{C}$-sodiumoctanoic acid (598 $\mu \mathrm{mol}$; Campro Scientific, Veenendaal, The Netherlands), dissolved in $1 \mathrm{ml}$ distilled water. Breath samples were taken at baseline, before the meal and from start of ingestion of the meal every 2 min the first $30 \mathrm{~min}$, every $5 \mathrm{~min}$ for the next $30 \mathrm{~min}$ and every $15 \mathrm{~min}$ thereafter up to $4 \mathrm{~h}$.

Three-dimensional ultrasonography

Total-, proximal-, and distal gastric volumes were assessed before and after ingestion of a nutrient drink using 3D-US [13-16]. Ultrasonographic data were acquired in a sitting position, while fasting and at 5, 15, 30, 45, and $60 \mathrm{~min}$ 
after ingestion of a nutrient drink. The nutrient drink $(500 \mathrm{ml})$ consisted of $200 \mathrm{ml}$ lactose- and fiber-free milk drink, containing $12.0 \mathrm{~g}$ proteins, $11.6 \mathrm{~g}$ fat and $36.8 \mathrm{~g}$ carbohydrate $(300 \mathrm{kcal})$ (Nutridrink, Nutricia, Zoetermeer, The Netherlands) mixed with $300 \mathrm{ml}$ of water, and was ingested within $3 \mathrm{~min}$.

The 3D imaging system consisted of an ultrasound scanner with a $3.5 \mathrm{MHz}$ curved probe and a tracking system (Esaote-Pie Medical, Maastricht, The Netherlands). The tracking system consisted of a transmitter generating a spatially varying magnetic field and a small receiver, firmly attached to the ultrasound probe, containing three orthogonal coils to sense the magnetic field strength [17]. A standardized ultrasound-scanning pattern was used, starting at the left lateral subcostal margin and then moving distally towards the pylorus having the probe in a vertical position [14]. The 2D sagittal planes were used to draw the region of interest, corresponding to the inner layer of the stomach wall (the interface between the outer profile of the gastric wall mucosa and the liquid nutrition). A 3D reconstructed image of the stomach and the gastric volume was obtained using software with rendering and volume estimation capability (In Vivo ScanNT, Medcom GmbH, Darmstadt, Germany).

The proximal gastric volume was defined as the gastric volume between the diaphragm and a dividing plane $10 \mathrm{~cm}$ below the point where the fundic top reaches the diaphragm. Similarly, a distal part was separated, defined as the gastric region between the antral area (the sagittal ultrasound plane in which the antrum, the left liver lobe, the superior mesenteric vein and the abdominal aorta are seen simultaneously) and the gastroduodenal junction [18]. At every time point, we subtracted fasting total or partial gastric volume leaving the change in total or partial gastric volume. Proximal and distal gastric volume ratios were calculated by dividing proximal or distal gastric volume by total gastric volume. Recently, we defined impaired proximal relaxation as the average of the proximal gastric volume ratios of 5 and $15 \mathrm{~min}$ smaller than the lower limit of the $95 \%$ confidence interval (0.32-0.57) of healthy controls; 35 healthy controls (16 male; mean age 31 (18-53) years) [7]. All measurements were made by a single investigator (N.v.L.) who was blinded for the results of the gastric emptying test and the drink test.

\section{Nutrient drink test}

The nutrient drink test was used to measure the drinking capacity and the symptoms evoked by a nutrient drink [19, 20]. Patients were asked to ingest a nutrient drink (Nutridrink; $1.5 \mathrm{kcal} / \mathrm{ml}$ ) at a constant rate of $15 \mathrm{ml} / \mathrm{min}$. At 5-min intervals, they scored satiety using a graphic rating scale that combines verbal descriptors on a scale graded $0-5$ ( $0=$ no satiety, $5=$ maximum satiety). The test ends when the subject reaches maximum satiety. In healthy controls, maximum satiety occurs after ingestion of $1005 \mathrm{ml}$ (1508 kcal). The lower limit of normal was $653 \mathrm{ml}$ (979 kcal) [19]. In the same study, FD patients ingested $361 \mathrm{ml}$ (542 kcal) before reaching maximum satiety.

\section{Statistical analysis}

The main focus of our analysis was (a) to analyse a possible relationship between the rate of gastric emptying, total or partial gastric volumes after meal ingestion, and drinking capacity, and (b) to compare the outcome of the ${ }^{13} \mathrm{C}$-octanoic breath test, the $3 \mathrm{D}$-US test, and the drink test with the symptoms of patients experienced during daily life (chronic symptoms).

The primary end points of the gastric function tests are dichotomous and continuous. The relationship between the outcomes of the three gastric function tests was studied using a Pearson's correlation between continuous variables (half-emptying time, retentions after $120 \mathrm{~min}$, fasting gastric volume, proximal gastric volume ratio, distal gastric volume ratio, and maximum drinking capacity). Secondly, patients were subdivided in two groups, according to postprandial proximal gastric relaxation (normal or impaired), and according to the rate of gastric emptying (normal or delayed), in order to compare multiple variables between the sub-groups using the Students' $t$-test.

Chronic upper abdominal symptoms (ordinal variables) were compared between FD patients with normal- or delayed gastric emptying or a normal or impaired proximal gastric relaxation (dichotomous variable), using the $\chi^{2}$ test. Secondly, the relationship between chronic upper abdominal symptoms and half-emptying time, retention after $120 \mathrm{~min}$, fasting gastric volume, proximal gastric volume ratio, distal gastric volume ratio, and maximum tolerated volume (continuous variable) was analysed using one-way analysis of variance (ANOVA).

We have analysed the effect of age, height, weight, BMI, and sex on the outcome of the gastric function tests and the chronic symptoms using a regression analysis. All variables were tested in single models and using multivariable analysis.

Due to the high number of comparisons made, we considered a $P$ value of $<0.01$ as statistically significant. All statistical analysis was performed using commercially available software (SPSS 11.0 for Microsoft windows). For the $\chi^{2}$ test and the Students' $t$-test, on the basis of a Cohen's effect size of 0.8 , a power of 0.80 was obtained with 60 subjects (considering $\alpha=0.01$ ) [21]. With the 
same number of subjects, there was good power (0.80) to detect an $\mathrm{R}$ value of 0.40 with an $\alpha=0.01$.

\section{Results}

Combined assessment of the ${ }^{13} \mathrm{C}$-octanoic breath test, 3DUS, and the nutrient drink test was performed in 60 FD patients. The frequency of upper abdominal sensations scored as moderate or higher was upper abdominal pain (80\%), early satiety (59\%), bloating (77\%), fullness $(71 \%)$, and nausea $(51 \%)$. Vomiting was present in $13 \%$ of patients (Table 1).

Gastric emptying and proximal gastric relaxation

Figure 1 shows the frequency of a delayed gastric emptying rate, defined as a half emptying time $\geq 120 \mathrm{~min}$ and/or a retention after $120 \mathrm{~min} \geq 40 \%$, and impaired proximal gastric relaxation, defined as an average proximal gastric volume ratio of 5 and $15 \mathrm{~min}$ postprandially $\leq 0.32(95 \%$ CI healthy controls) in the patient group [7]. A delayed gastric emptying with a normal proximal gastric relaxation was found in $33 \%$ of patients. Impaired proximal gastric relaxation with a normal gastric emptying rate was observed in $23 \%$ of patients. In $38 \%$ of all patients, none of both pathophysiologic disorders were found. Finally, only a small overlap exists between the two pathophysiologic disorders (5\% of patients). These numbers are in concordance with literature $[5,6]$.

Nutrient drink test

The average amount of nutridrink ingested before reaching maximum satiety was 399.8 (344-447) ml (600 kcal). Table 2 summarizes the results of the nutrient drink test. No effect of age or BMI on MTV and upper abdominal sensations was observed (all $P>0.01$ ). Male patients had a

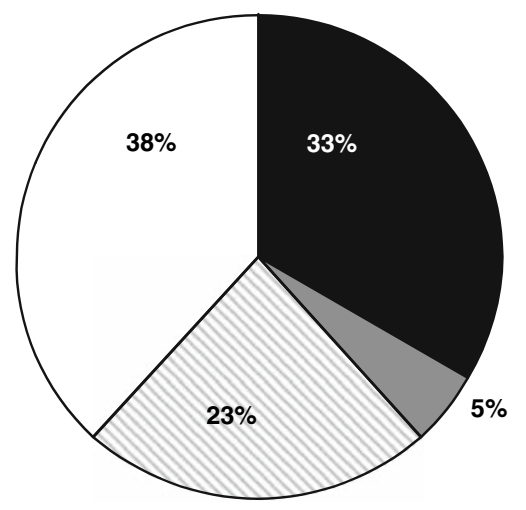

Fig. 1 Gastric emptying and proximal gastric relaxation in 60 FD patients: $33 \%$ of patients have a delayed gastric emptying and normal proximal gastric relaxation (black), $23 \%$ of patients have impaired proximal gastric relaxation and a normal gastric emptying rate (striped), 38\% of patients have none of the pathophysiologic disorders (white), and $5 \%$ of patients have both disorders (grey)

maximum tolerated volume (MTV) of 500 (381-618), and female patients of 359 (301-417) $(P=0.017)$.

Relationship between gastric emptying, total and partial gastric volume, and drinking capacity

Table 3 displays some of the patient characteristics in FD patients with normal or impaired proximal gastric relaxation and with normal or delayed gastric emptying. Age or BMI did not influence proximal gastric relaxation or the rate of gastric emptying. Patients with a normal gastric emptying rate had an MTV of $439 \mathrm{ml}$ (359-519) whereas patients with a delayed gastric emptying had a MTV of $334 \mathrm{ml}(279-389)(P=0.032)$. MTV in patients with normal or impaired proximal relaxation was very similar (404 and $384 \mathrm{ml}$ respectively). In patients with normal proximal gastric relaxation, an average fasting gastric volume of $50 \mathrm{ml}$ (41-59) was determined, opposed to $34 \mathrm{ml}(24-44)$ in patients with impaired proximal relaxation $(P=0.029)$. The fasting gastric volume in patients with normal or delayed gastric emptying was 44 and $47 \mathrm{ml}$, respectively.

Table 1 Frequency of severity grading for each of six dyspeptic symptoms in 60 dyspeptic patients (chronic symptoms)

\begin{tabular}{lcccc}
\hline & 0 (None) & $1-2$ (Very mild-mild) & 3 (Moderate) & $4-5$ (Severe-very severe) \\
\hline Upper abdominal pain & $1(2)$ & $11(18)$ & $18(30)$ & $30(50)$ \\
Early satiety & $7(12)$ & $18(30)$ & $19(32)$ & $16(27)$ \\
Bloating & $4(7)$ & $10(17)$ & $27(45)$ & $19(32)$ \\
Fullness & $2(3)$ & $15(25)$ & $26(43)$ & $17(28)$ \\
Nausea & $10(17)$ & $19(32)$ & $14(23)$ & $17(28)$ \\
Vomiting & $46(77)$ & $6(10)$ & $2(3)$ & $6(10)$ \\
\hline
\end{tabular}

Numbers in parentheses represent row percentages 
Table 2 The effect of age, BMI, and sex on maximum tolerated volume (MTV) and the change in upper abdominal sensations after the nutrient drink test

\begin{tabular}{|c|c|c|c|c|c|c|}
\hline & \multicolumn{2}{|l|}{ Age } & \multicolumn{2}{|l|}{ BMI } & \multicolumn{2}{|l|}{ Sex } \\
\hline & $\beta_{0}$ & $\beta_{1}$ & $\beta_{0}$ & $\beta_{1}$ & Female & Male \\
\hline MTV & $329(160-499)$ & $1.7(-2.2-5.6)$ & $363(3-725)$ & $1.6(-14-18)$ & $359(301-417)$ & $500(381-618)$ \\
\hline \multicolumn{7}{|c|}{ Delta symptoms } \\
\hline Pain & $11(0-35)$ & $0.02(-0.5-0.6)$ & $24(0-74)$ & $-0.5(-3-2)$ & $10(0-20)$ & $14(0-28)$ \\
\hline Fullness & $49(23-76)$ & $-0.1(-0.7-0.5)$ & $49(0-100)$ & $-0.1(-2-2)$ & $48(37-59)$ & $42(29-55)$ \\
\hline Nausea & $46(20-72)$ & $-0.5(-1-0.1)$ & $28(0-85)$ & $-0.2(-3-2)$ & $21(11-31)$ & $31(12-50)$ \\
\hline Hunger & $-28(-50-0)$ & $0.09(-0.4-0.6)$ & $-7(-52-40)$ & $-0.8(-3-1.2)$ & $-24(-33$ to -15$)$ & $-25(-37$ to -14$)$ \\
\hline
\end{tabular}

$\beta_{0}$ : intercept of the model. $\beta_{1}$ : slope of the corresponding variable. Numbers in parenthesis represent the $95 \%$ confidence interval of $\beta_{\mathrm{I}}$. MTV and delta symptoms in female and male patients are presented as mean ( $95 \%$ confidence interval for mean). No effect of age, BMI, or sex on MTV or the change in upper abdominal sensations after the nutrient drink test was observed (all $P>0.01$ )

Table 3 Characteristics of FD patients, subdivided according to the extent of proximal gastric relaxation or the rate of gastric emptying $(n=60)$

\begin{tabular}{lcccc}
\hline & \multicolumn{2}{l}{ Proximal gastric relaxation } & & \multicolumn{2}{l}{ Gastric emptying } \\
\cline { 2 - 3 } & Normal $(n=43)$ & Impaired $(n=17)$ & & Normal $(n=37)$ \\
\hline Age & $41(36-45)$ & $42(35-49)$ & $40.9(36-45)$ & Delayed $(n=23)$ \\
BMI & $22(21-23)$ & $23(21-25)$ & $22(21-23)$ & $41(35-48)$ \\
MTV $(\mathrm{ml})$ & $404(346-461)$ & $384(237-530)$ & $439(359-519)$ & $334(279-389)$ \\
Fasting gastric volume $(\mathrm{ml})$ & $50(41-59)$ & $34(24-44)$ & $44(33-55)$ & $47(37-56)$ \\
\hline
\end{tabular}

Data are presented as mean (95\% confidence interval for mean). No effect of age and BMI on proximal gastric relaxation or gastric emptying was observed

Twenty out of 43 female patients had a delayed gastric emptying $(47 \%)$ and $18 \%$ of all male patients had a delayed gastric emptying $(P=0.038)$. The prevalence of impaired proximal gastric relaxation in male and female patients was $21 \%$ and $35 \%$ respectively (not shown in the table).

A positive correlation was observed between the proximal gastric volume ratio (3D-US) and half emptying time $(r=0.32, P=0.015)$ and the retention after $120 \mathrm{~min}$ $(r=0.30, P=0.024)\left({ }^{13} \mathrm{C}\right.$ breath test). No correlation was found between the distal gastric volume ratio and the main outcome parameters of the gastric emptying test.

Relationship between chronic symptoms and gastric function

No effect of age, sex, or BMI on any of the chronic upper abdominal sensations was observed, except that patients with a higher BMI or a higher weight scored lower on symptoms of early satiety (both $P=0.007$ ). Figure 2 shows the chronic upper abdominal symptoms in FD patients with normal or delayed gastric emptying and normal or impaired proximal gastric relaxation. No differences were observed in the percentage of patients who scored any of the upper abdominal symptoms as moderate or higher between these groups (all $P>0.01$ ). We did not find any correlation between half emptying time, retention after 120 min, proximal gastric volume ratio, distal gastric volume ratio, fasting gastric volume, and any of the chronic upper abdominal symptoms (all $P>0.01$ ).

Figure 2 depicts all FD patients categorized according to their chronic complaints; mild (1-2), moderate (3), and severe (4-5). No difference in maximum drinking capacity was observed between the three groups (all $P>0.01$ ) (Fig. 3). Interestingly, patients who reported early satiety as moderate or higher have a comparable drinking capacity with patients who do not experience this symptom in daily life.

\section{Discussion}

The following were the most important findings of this study: (1) no relationship was found between chronic upper abdominal symptoms and gastric function (proximal gastric relaxation, gastric emptying rate, or drinking capacity), (2) a third of all FD patients had a normal gastric emptying rate and a normal proximal gastric relaxation, and only a small overlap existed between the two pathophysiologic disorders (7\%), and (3) there was an absence of any 

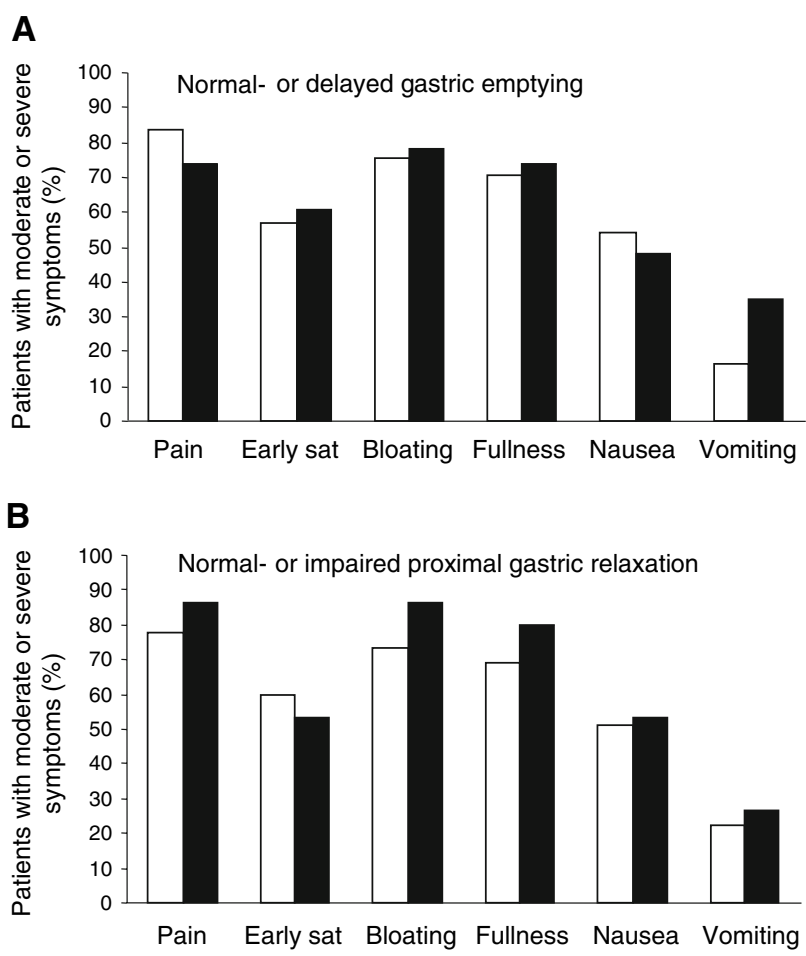

Fig. 2 Chronic upper abdominal symptoms scored from 0 (nonexistent) to 5 (very severe; incapacitating with inability to work or do usual activity). The figure shows the number of the patients who scored three (moderate) or higher on the questionnaire (expressed as a percentage of the total) in subgroups with; (Fig. 1A) normal- ( $\square$ ) or delayed (ם) gastric emptying, and (Fig. 1B) normal- ( $\square$ ) or impaired (ם) proximal relaxation

relationship between maximum drinking capacity and proximal gastric relaxation or gastric emptying rate.

The observation that approximately $40 \%$ of FD patients had a delayed gastric emptying, and approximately $30 \%$ of FD patients had impaired proximal gastric relaxation, is confirmatory of previous studies [5, 6]. The relative small overlap between the two pathophysiologic mechanisms may suggest that one abnormality excludes the other. However, no significant positive correlation between the proximal gastric volume ratio and half emptying time or retention after $120 \mathrm{~min}$ was found. The rate of gastric emptying is most likely dependent on many factors, including fundal, antral, pyloric, and duodenal motility [22]. For that reason, gastric emptying and postprandial gastric relaxation should be considered as two separate mechanisms [23].

For assessment of partial gastric volumes we used 3D-US as a noninvasive alternative for the barostat technique. Recently, a head-to-head comparison between the barostat and 3D-US was performed, in which it was shown that 3D-US was able to identify almost all patients with impaired accommodation assessed by barostat. It was, however, emphasized that the two techniques are not interchangeable, which is likely to be due to the difference in invasiveness of both techniques. Since there is no absolute concordance between the two techniques, we must preserve some reservations in generalizing the results of the current study.

The nutrient drink test has been suggested as a tool to measure meal-induced satiety, and as a non-invasive alternative for the detection of normal- or impaired accommodation of the stomach [6, 19]. Furthermore, a positive relationship between the rate of gastric emptying and the amount of Kcal ingested during the nutrient drink test has been described, thereby suggesting that the maximum tolerated volume is not only influenced by gastric accommodation [24]. However, many studies have shown conflicting results, displaying no relationship between drinking capacity and barostat or SPECT findings, [25, 26] and a negative relationship between gastric emptying rate and maximum tolerated volume [27].

Since the results from different studies do not correspond, it remains a mystery what it is we are testing with the nutrient drink test. The suggestion that the nutrient drink test can be used to discriminate between FD patients with normal or impaired visceral sensitivity is disputable [9]. In the current study, we did not observe any relationship between MTV and chronic upper abdominal symptoms or between MTV and proximal gastric relaxation or gastric emptying rate. Most studies do agree that the drink test differentiates between FD patients and healthy controls, as we have found in the present study. Notably, the average amount of nutridrink ingested until maximum satiety, was very similar to what others have found (approximately $360 \mathrm{ml}$ ) [19], which is below the 95\% confidence interval of healthy controls. No effect of age or BMI on MTV was observed in the current study, however we did observe a modest effect of gender, although this did not reach statistical significance $(P=0.017)$ [20].

The nutrient drink test is also being used in pharmacological trials, and a resemblance between symptoms evoked by the meal challenge and symptoms experienced in daily life has been observed [27]. Recently, we have performed a double blind, placebo-controlled, crossover trial, in which the activity of a new drug was tested, using the outcome of the nutrient drink test as one of the end points in the study [28]. FD patients who participated in the pharmacological trial drank significantly more compared to the FD patients in the current study; $569 \pm 90 \mathrm{ml}$ and $360 \pm 30 \mathrm{ml}$ respectively $(P<0.001)$. A strong placebo effect and cognitive influences like motivation should therefore be considered as confounding factors. No differences in age, sex, BMI, chronic symptoms, or upper abdominal sensations experienced during the drink test were observed between the patients who participated in the pharmacological trial and those who did not. 
Fig. 3 Nutrient drink test: maximum tolerated volume in FD patients, categorized according to the chronic symptoms. No difference in drinking capacity was observed between patients experiencing mild (1-2), moderate (3), or severe (4-5) pain, early satiety, fullness, or nausea in daily life (all $P>0.01$ )
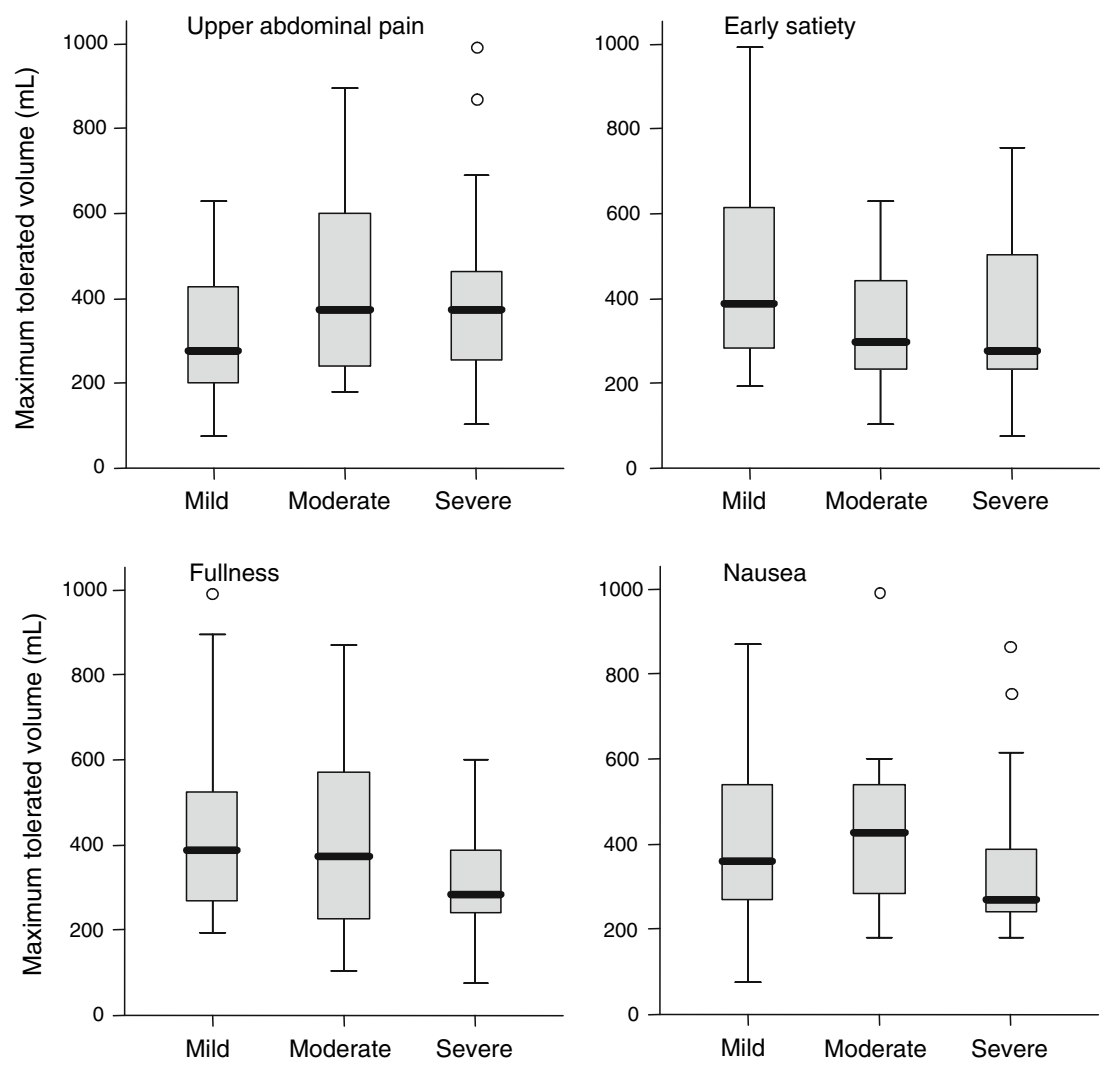

In summary, the maximum drinking capacity of $\mathrm{FD}$ patients, seen at a tertiary referral practice, is not influenced by gastric emptying rate or proximal gastric relaxation. The question is raised what usefulness this test has, in terms of diagnosis or treatment options, in FD patients and as a tool to analyze gastric function or upper abdominal sensations. Since we did not find any relationship between upper abdominal symptoms and MTV, the nutrient drink test cannot be regarded as an alternative for measuring visceral perception, as can be done by gastric barostat. In our opinion, many subjective factors, like motivation, probably play an important disturbing factor in the outcome of the test.

In conclusion, in spite of a high prevalence of impaired proximal accommodation and delayed gastric emptying in FD patients, the lack of correlation between chronic upper abdominal sensations and gastric function questions the role of these pathophysiologic mechanisms in the generation of symptoms. Consequently, gastric function does not serve as a clear marker for the symptoms experienced by FD patients in daily life, and limited effect on symptoms may be expected when targeting these specific mechanisms. Finally, despite many efforts, no (measurable) motoric disorder can be appointed as a possible pathophysiologic mechanism underlying the presence of upper abdominal symptoms. Most likely, other factors like visceral perception play a vital role in functional dyspepsia.

\section{References}

1. Talley NJ, Stanghellini V, Heading RC, Koch KL, Malagelada JR, Tytgat GN (1999) Functional gastroduodenal disorders. Gut 45(Suppl 2):II37-II42

2. Feinle-Bisset C, Vozzo R, Horowitz M, Talley NJ (2004) Diet, food intake, and disturbed physiology in the pathogenesis of symptoms in functional dyspepsia. Am $\mathrm{J}$ Gastroenterol 99(1):170-181

3. Cremonini F, Delgado-Aros S, Talley NJ (2004) Functional dyspepsia: drugs for new (and old) therapeutic targets. Best Pract Res Clin Gastroenterol 18(4):717-733

4. Tack J, Lee KJ (2005) Pathophysiology and treatment of functional dyspepsia. J Clin Gastroenterol 39(4 Suppl 3):S211-S216

5. Stanghellini V, Tosetti C, Barbara G, Morselli-Labate AM, Monetti N et al (1996) Risk indicators of delayed gastric emptying of solids in patients with functional dyspepsia. Gastroenterology 110(4):1036-1042

6. Tack J, Piessevaux H, Coulie B, Caenepeel P, Janssens J (1998) Role of impaired gastric accommodation to a meal in functional dyspepsia. Gastroenterology 115(6):1346-1352

7. van Lelyveld N, Scheffer R, Mundt M, Samsom M (2006) Partial gastric volumes and upper abdominal sensations in functional dyspeptic and GERD patients: a 3D ultrasonographic study. Am J Gastroenterol 101(8):1845-1852

8. Salet GA, Samsom M, Roelofs JM, Berge Henegouwen GP, Smout AJ, Akkermans LM (1998) Responses to gastric distension in functional dyspepsia. Gut 42(6):823-829

9. Boeckxstaens GE, Hirsch DP, Kuiken SD, Heisterkamp SH, Tytgat GN (2002) The proximal stomach and postprandial symptoms in functional dyspeptics. Am J Gastroenterol 97(1):40-48

10. Verhagen MA, Samsom M, Maes B, Geypens BJ, Ghoos YF, Smout AJ (1997) Effects of a new motilide, ABT-229, on gastric 
emptying and postprandial antroduodenal motility in healthy volunteers. Aliment Pharmacol Ther 11(6):1077-1086

11. Tucci A, Corinaldesi R, Stanghellini V, Tosetti C, Di Febo G, Paparo GF et al (1992) Helicobacter pylori infection and gastric function in patients with chronic idiopathic dyspepsia. Gastroenterology 103(3):768-774

12. Samsom M, Vermeijden JR, Smout AJ, Van Doorn E, Roelofs J, Van Dam PS et al (2003) Prevalence of delayed gastric emptying in diabetic patients and relationship to dyspeptic symptoms: a prospective study in unselected diabetic patients. Diab Care 26(11):3116-3122

13. Gilja OH, Detmer PR, Jong JM, Leotta DF, Li XN, Beach KW et al (1997) Intragastric distribution and gastric emptying assessed by three-dimensional ultrasonography. Gastroenterology 113(1):38-49

14. Scheffer RC, Gooszen HG, Wassenaar EB, Samsom M (2004) Relationship between partial gastric volumes and dyspeptic symptoms in fundoplication patients: a 3D ultrasonographic study. Am J Gastroenterol 99(10):1902-1909

15. Scheffer RC, Gooszen HG, Hebbard GS, Samsom M (2005) The role of transsphincteric pressure and proximal gastric volume in acid reflux before and after fundoplication. Gastroenterology 129(6):1900-1909

16. Mundt MW, Samsom M (2006) Fundal dysaccommodation in functional dyspepsia: head-to-head comparison between the barostat and three-dimensional ultrasonographic technique. Gut 55(12): $1725-1730$

17. Tefera S, Gilja OH, Olafsdottir E, Hausken T, Hatlebakk JG, Berstad A (2002) Intragastric maldistribution of a liquid meal in patients with reflux oesophagitis assessed by three dimensional ultrasonography. Gut 50(2):153-158

18. Bolondi L, Bortolotti M, Santi V, Calletti T, Gaiani S, Labo G (1985) Measurement of gastric emptying time by real-time ultrasonography. Gastroenterology 89(4):752-759

19. Tack J, Caenepeel P, Piessevaux H, Cuomo R, Janssens J (2003) Assessment of meal induced gastric accommodation by a satiety drinking test in health and in severe functional dyspepsia. Gut 52(9):1271-1277

20. Chial HJ, Camilleri C, Delgado-Aros S, Burton D, Thomforde G, Ferber I et al (2002) A nutrient drink test to assess maximum tolerated volume and postprandial symptoms: effects of gender, body mass index and age in health. Neurogastroenterol Motil 14(3):249-253

21. Cohen J (1988) Statistical power analysis for the behavioral sciences, 2nd ed. Erlbaum, Hillsdale, New Jersey

22. Fraser RJ, Horowitz M, Maddox AF, Dent J (1994) Postprandial antropyloroduodenal motility and gastric emptying in gastroparesis-effects of cisapride. Gut 35(2):172-178

23. Troncon LE, Bennett RJ, Ahluwalia NK, Thompson DG (1994) Abnormal intragastric distribution of food during gastric emptying in functional dyspepsia patients. Gut 35(3):327-332

24. Cuomo R, Sarnelli G, Grasso R, Bruzzese D, Pumpo R, Salomone $M$ et al (2001) Functional dyspepsia symptoms, gastric emptying and satiety provocative test: analysis of relationships. Scand J Gastroenterol 36(10):1030-1036

25. Boeckxstaens GE, Hirsch DP, van den Elzen BD, Heisterkamp SH, Tytgat GN (2001) Impaired drinking capacity in patients with functional dyspepsia: relationship with proximal stomach function. Gastroenterology 121(5):1054-1063

26. Gonenne J, Castillo EJ, Camilleri M, Burton D, Thomforde GM, Baxter KL et al (2005) Does the nutrient drink test accurately predict postprandial gastric volume in health and community dyspepsia? Neurogastroenterol Motil 17(1):44-50

27. Delgado-Aros S, Camilleri M, Cremonini F, Ferber I, Stephens D, Burton DD (2004) Contributions of gastric volumes and gastric emptying to meal size and postmeal symptoms in functional dyspepsia. Gastroenterology 127(6):1685-1694

28. van Lelyveld N, Ter Linde J, Baron A, Mundt M, Wajs E, Samsom M (2006) The 5-HT4 antagonist R216073 does not affect gastric motor and sensory function in patients with functional dyspepsia. Aliment Pharmacol Ther 24(4):669-677 